\title{
ADVANCES IN LIDAR OBSERVATIONS FOR AIRBORNE HAZARDS FOR AVIATION IN THE FRAMEWORK OF THE EUNADICS-AV PROJECT
}

\author{
Arnoud Apituley ${ }^{1}$,*, Lucia Mona ${ }^{2}$, Nikolas Papagiannopoulos ${ }^{2}$, Rolf Rufenacht ${ }^{3}$, \\ Saskia Wagenaar $^{1}$, Piet Stammes ${ }^{1}$, Jos de Laat ${ }^{1}$, Wim Som de Cerff ${ }^{1}$, Marijn de Haij ${ }^{1}$, \\ Francesco Marchese $^{2}$, Alfredo Falconieri ${ }^{2}$, Alexander Haefele ${ }^{3}$ and Maxime Hervo 3 \\ ${ }^{1}$ Royal Netherlands Meteorological Institute (KNMI), The Netherlands, *apituley@knmi.nl \\ ${ }^{2}$ IMAA-CNR, Potenza, Italy \\ $3_{\text {MeteoSwiss, Payerne, Switzerland }}$
}

\begin{abstract}
The vulnerability of the (European) aviation system to the airborne hazards was evident during the Eyjafjallajökull volcanic eruption in 2010. For support of Air Traffic Control (ATC) many observations of the event were available from satellites, ground based instruments and airborne platforms, at pan-European scale. However, efficient use of the data for ATC proved difficult mainly due to sub-optimal aggregation and integrated assessment of the available information in near-real-time.
\end{abstract}

The project EUNADICS-AV (European Natural Disaster Coordination and Information System for Aviation) aims to close this gap. The observational component of the project will make existing data products for airborne hazards more accessible, visible and used, and to foster tailored product development. Once assimilated into models and integrated in the EUNADICS-AV Data Portal these data can be the base to efficiently improve European airspace resilience to airborne hazards.

Since 2010 new data products have become available specifically for for airborne hazard alerting and monitoring together with specific tailored products designed for replying to user needs and recommendations.

This paper describes the EUNADICS-AV approach and will focus on the role of operational and research grade ground based lidars.

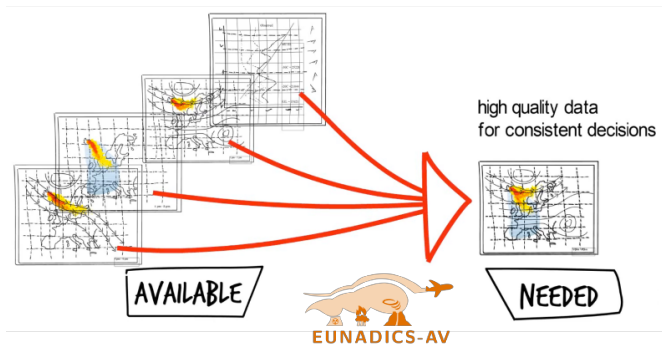

Figure 1 The EUNADICS-AV project aims to make existing data products for airborne hazards more accessible, visible and used.

\section{INTRODUCTION}

Aviation is one of the most critical transport systems of our time. Even short interruptions in flight schedules will cause major economic damage. The main objective of the H2020 EUNADICS-AV project (2016-2019) is closing the significant gap in data and information availability during airborne hazards resulting from environmental emergency scenarios and nuclear incidents, that affect air traffic. The focus is on atmospheric aerosols with trace gases used as indicators for: desert dust storms, forest fires, volcanic eruptions, and nuclear incidents (6).

The environmental emergencies the project focusses on are considered rare, but with an extremely high impact such as volcanic eruptions. The observational component of the project aims to provide integrated and advanced data sets of atmospheric constituents relevant to the project goal. The observational datasets from satellite, ground based remote sensing and air- borne in-situ measurements, are the base for the 
development of an Early Warning System and for the assimilation into dispersion models. EUNADICS-AV activities in this sense aim to foster the use of the existing data in a more efficient way and develop new products specific tailored for this kind of applications. This is illustrated in Fig.1.

In this paper we focus on the role of ground based lidar network data in the project.

\section{OBSERVATION INFRASTRUCTURE}

To support the EUNADICS-AV goals, observations are needed that will be assimilated in models that subsequently provide high-quality 3D-maps of the affected hazard areas. The main priorities for observations are: 1) tailored products that can improve situational awareness (e.g. high resolution, NRT availability, global coverage, low and characterized uncertainty; 2) satellite / airborne visualisation of hazard identification, 3) visualisation of lidar imagery for volcanic ash identification.

Among the novel observations available within EUNADICS-AV are the aerosol and trace gas observations at much improved spatial resolution of $3.5 \times 7 \mathrm{~km}^{2}$ at nadir provided by TROPOMI on board of the Copernicus Sentinel-5p polar orbiting satellite. TROPOMI has already shown its high potential in detecting and monitoring with high definition desert dust, volcanic plumes and forest fires (3).

In EUNADICS-AV data from space-borne, ground based remote sensing and in-situ air- borne sensors are used. Here we focus on the ground based lidar data and refer to the link to satellite data and models.

\subsection{Ground based observations}

\subsubsection{ACTRIS-EARLINET}

ACTRIS (Aerosol, Clouds and Trace Gases Research Infrastructure) is a pan-European research infrastructure

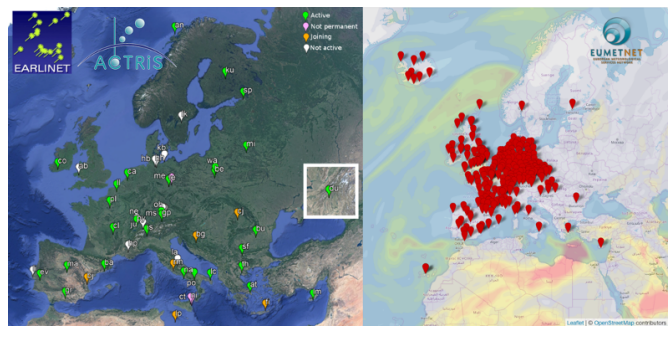

Figure 2 Maps of ACTRIS-EARLINET stations (left) and of the EUMETNET automated lidar ceilometer network (right).

consolidating actions amongst European partners producing high- quality observations of aerosols, clouds and trace gases (1). To address many societal and environmental challenges, such as air quality, health, sustainability and climate change, detailed knowlede of atmospheric processes is needed. ACTRIS contributes to resolving these challenges by offerring a platform for re- searchers to combine their efforts effectively, and by providing open and free observational data of aerosols, clouds and trace gases.

Part of ACTRIS is EARLINET (Fig.2), the European Aerosol Research Lidar Network, with the goal of creating a quantitative, comprehensive, and statistically significant database for the horizontal, vertical, and temporal distribution of aerosols on a continental scale. Aerosol Raman lidars are the backbone of the network. At most stations the lidars measure at multiple wavelenths (1064, 532 and $355 \mathrm{~nm}$ ) and include depolarisation channels (10).

These properties of the EARLINET lidars enable retrieval of aerosol optical properties (backscatter, extinction, lidar ratio), as well as microphysical aerosol properties, such as effective size (9), and distinction of particle shapes through the use of polarisation data. These abilities have proven invaluable in analysis of volcanic ash plumes (11), desert dust plumes as well as forest fires. In addition, it should be stressed that from well-calibrated depolarisation lidar data, an estimate of the volcanic ash mass 

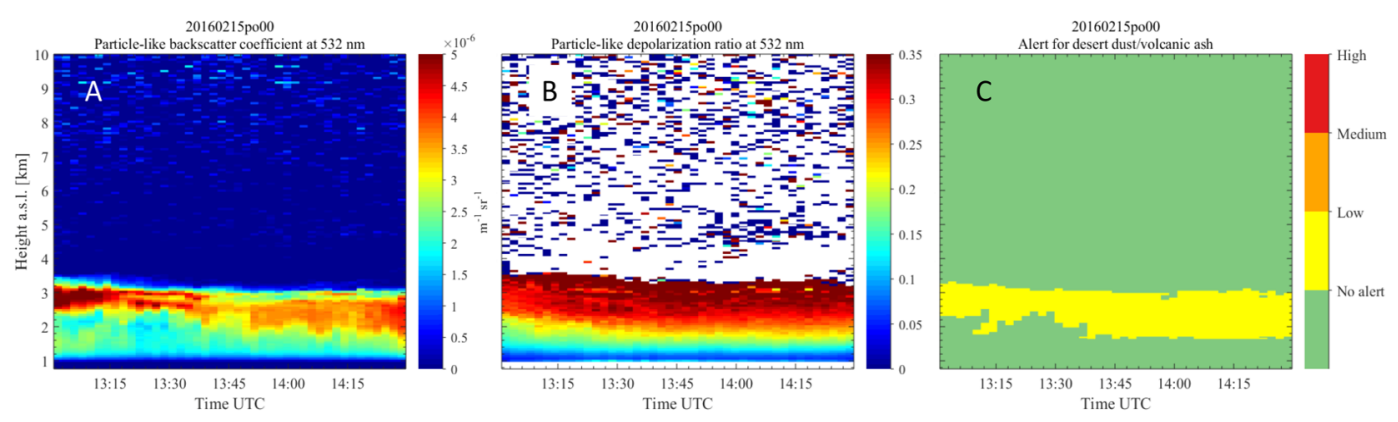

Figure 3 Example of a tailored data product applied for Saharan dust over Potenza (It). A. Backscatter profiles at $532 \mathrm{~nm}, B$. Particle depolarisation ratio at $532 \mathrm{~nm}$, C. the resulting altitude dependent alert levels.

concentration, which is the quintessential parameter needed to decide on safe versus hazardous airspace, can be made (7), even in near- real-time (8).

\subsubsection{E-Profile ALC Network}

EUMETNET is a grouping of 31 European National Meteorological Services that provides a framework to organise cooperative programmes between its members in the various fields of basic meteorological activities. These activities include observing systems, data processing, basic forecasting products, research and development and training.

The E-PROFILE Programme manages the European network of radar wind profilers and automatic lidars and ceilometers (ALC) for the monitoring of vertical profiles of wind and aerosols including volcanic ash (2).

Due to technical advances of the last years, ceilometers, originally designed to provide cloud base height, now also measure the vertical distribution of aerosols derived from the backscatter profile. To make this new observation capacity available EPROFILE has developed a framework to produce and exchange profiles of attenuated backscatter profiles. ALCs of stations across Europe are added to the operational network (Fig.2). One of the goals for the ALC network is to liaise with International Programmes. Use of the data within EUNADICS-AV is an excellent example.

\subsection{Lidar generated alert masks}

The EARLINET Single Calculus Chain (SCC) delivers high resolution data: the calibrated total attenuated backscatter and the calibrated volume depolarization ratio time series. From these profiles, new high resolution parameters can be derived, such as particle-like intensive properties, and provide the basis of a NRT particle classification mask. A decision tree based on threshold criteria identifies dust/ash layers and associated risk levels for aviation (Fig.3).

\subsection{Space Borne Observations and Models}

The lidar information can now be merged with satellite information (such as from existing mechanisms like SACS (Support to Aviation Control Service) and models into a color-coded map that according to the ash/dust hazard level.

\section{DATA PORTAL INTEGRATION}

Based on the VAAC (Volcanic Ash Advisory Center) needs $(4 ; 5)$, quicklooks of the lidar data from across European from EARLINET and products from EPROFILE, will be made disseminated through the interactive EUNADICS-AV portal (Fig.4). The portal also displays satellite data and output from models that have assimilated the lidar and satellite data in near-real-time. Additionally, a new tailored ACTRIS/EARLINET products is under investigation for the NRT identification of dust/ash cloud, to be made available through EUNADICS-AV and ingested in the Early Warning System. 


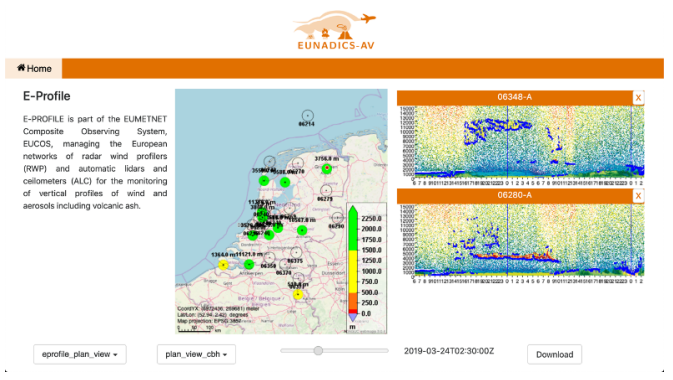

Figure 4 Example of display of e-profile $A L C$ data in the interactive EUNADICS-AV data portal. The interactive interface enables, amongst others, selection of multiple stations and data sets and allows continuous through time with live updates.

\section{CONCLUSIONS}

In EUNADICS-AV lidar data plays a major role for detection of aerosol plumes during events that impact aviation. In case of emergencies like these, availability of reliable data in near- real-time is essential for efficient air traffic control. The operational automated lidar ceilometers (ALC) in E-PROFILE provide quality controlled data in a relatively dense network. However, ALCs are limited in capabilities for quantitative aerosol profiling. Therefore, the ALC network and the much more advanced capabilities of the quantitative aerosol lidars in EARLINET provide a unique combination of information for the tasks defined in EUNADICS-AV. Further combination with space-borne data provides a solid basis for the information needed to make airspace safer in the presence of airborne disasters.

Within the EUNADICS-AV project a frame- work for the integration of observations, mod els and data visualisation and dissemination has been set up and is available, for further optimisation, and eventually operationalisation.

\section{ACKNOWLEDGEMENTS}

This work received funding from the EC Horizon 2020 Research and Innovation Programme, Grant Agreement no.723986.

\section{REFERENCES}

[1] actris.eu.

[2] ceilometer.e-profile.eu.

[3] https://apps.sentinel-hub.com/eo-browser.

[4] https://www.metoffice.gov.uk/aviation/va ac/.

[5] http://www.meteo.fr/vaac.

[6] www.eunadics.eu.

[7] A. Ansmann, et al. Ash and fine-mode particle mass profiles from EARLINETAERONET observations over central Europe after the eruptions of the Eyjafjallajökull volcano in 2010. J. Geophys. Res., 116, 062011.

[8] D. P. Donovan and A. Apituley. Practi-cal depolarization-ratio-based inversion procedure: lidar measurements of the Eyjafjallajökull ash cloud over the Netherlands. Appl. Opt., 52(11):2394-2415, Apr 2013.

[9] D. Müller, et al. Microphysical parti- cle properties derived from inversion algo- rithms developed in the framework of ear- linet. Atmospheric Measurement Techniques, 9(10):5007-5035, 2016.

[10] G. Pappalardo, et al. Earlinet: towards an ad- vanced sustainable european aerosol lidar net- work. Atmospheric Measurement Techniques, 7(8):2389-2409, 2014.

[11] G. Pappalardo, et al. Four-dimensional dis- tribution of the 2010 eyjafjallajökull volcanic cloud over europe observed by earlinet. Atmo- spheric Chemistry and Physics, 13(8):4429- 4450, 2013. 